\title{
É economicamente viável regionalizar a atuação de um hospital público de médio porte?
}

| ${ }^{1}$ Paulo César de Souza, ${ }^{2}$ João Henrique G. Scatena |

Resumo: A eficiência dos serviços públicos de saúde é uma necessidade administrativa crescente, especialmente nos hospitais do SUS. Essas organizações são complexas em virtude da multiplicidade de serviços prestados e dos altos custos envolvidos. Nessa linha, este artigo avalia um hospital do Estado de Mato Grosso, através do método de "análise de custovolume-superávit". Os resultados demonstram, entre outros, que a redução da capacidade ociosa, a partir do aumento do número de pacientes de outros municípios, produziria um aumento de receita em virtude das economias de escala, dotando o processo de descentralização do SUS (microrregionalização) de eficiência sistêmica.

> Palavras-chave: Avaliação econômica, custos hospitalares, gestão hospitalar.

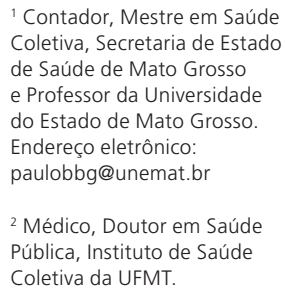

${ }^{2}$ Médico, Doutor em Saúde Pública, Instituto de Saúde Coletiva da UFMT.

Recebido em: 08/07/2009 Aprovado em: 10/12/2009. 
A provisão de serviços hospitalares e a busca pela eficiência dessas organizações têm tornado a gestão dos sistemas de serviços de saúde um processo de grande complexidade. Uma das razões é a multiplicidade de objetivos desse sistema, os quais são: equidade, eficácia, eficiência, qualidade e satisfação do usuário. Dentre esses, destaca-se, para os fins deste trabalho, a eficiência, ou seja, "a relação favorável entre os resultados obtidos e os recursos alocados" (MENDES, 1998, p. 57).

A complexidade dos serviços de saúde deve-se, também, ao modelo presente no cenário internacional, apresentando uma tendência de descentralização desses serviços, contrapondo-se ao antigo modelo centralizado (MG, 2004). Embora apresente pontos positivos, a descentralização dos serviços de saúde tem revelado também debilidades, dentre as quais se destacam: dificuldade de coordenação, incremento dos custos de transação, aumento das desigualdades, ineficiência por perda de escala e escopo, fragmentação dos serviços e escassez de recursos gerenciais (MENDES, 2001).

Estudos comparativos realizados nos sistemas de serviços de saúde do Chile, Colômbia e Bolívia demonstraram que a descentralização produziu algum aumento na equidade. No entanto, não foi possível evidenciar resultados positivos em relação à eficiência e à qualidade dos serviços (BOSSERT apud MG, 2004).

No Brasil, a descentralização foi realizada utilizando o paradigma da municipalização autárquica, a qual deu aos municípios a autonomia sobre as ações de saúde no seu território. Em função disso, muitos serviços foram pulverizados, muitos hospitais construídos funcionam com taxas de ocupação baixas e laboratórios com pequeno número de exames. Esse processo leva a deseconomias de escala e perda de eficiência e qualidade nos serviços, já que em alguns deles, como o de apoio diagnóstico e terapêutico, por exemplo, a qualidade está relacionada a uma significativa base quantitativa (MENDES, 2001). Segundo o Conass (2006), o desenvolvimento do parque hospitalar público brasileiro, seguindo essa tendência de abertura de diversos pequenos hospitais, estava sendo feito na contramão da experiência internacional, a qual relata o fechamento de hospitais menores e a concentração de serviços em hospitais maiores, obtendo ganhos de escala e na qualidade. Assim, o aumento da eficiência e a melhoria na qualidade colocam-se como desafios para o sistema de saúde brasileiro. 
No Brasil, o subfinanciamento da saúde tem agigantado esses desafios. Segundo CONASS (2006), entre 2000 e 2005, as receitas correntes do Governo Federal aumentaram da proporção $18,6 \%$ para $22,4 \%$ do PIB, no entanto, as despesas do Ministério da Saúde decresceram no mesmo período, de 8,1\% para $7,2 \%$ das receitas correntes. Esse subfinanciamento tem dificultado o efetivo cumprimento dos princípios e diretrizes do Sistema Único de Saúde, além de agravar a ineficiência do sistema.O subfinanciamento dificulta a estruturação de carreira dos profissionais, principalmente dos médicos, sendo este outro agravante da ineficiência do sistema. Dessa forma, verifica-se que a busca pela eficiência pode requerer algumas vezes o acréscimo de recursos, de modo a atender no mínimo às necessidades básicas e propiciar condições que conduzam à eficiência.

A alternativa que tem sido buscada para minimizar o subfinanciamento é a regulamentação da Emenda Constitucional 29, a qual estabelece um limite mínimo de recursos que o Governo Federal deve aplicar à Saúde, além de definir com mais clareza o que é considerado ação ou serviço de saúde. Diante desses desafios, surgiram iniciativas no sentido de mudar do paradigma da municipalização autárquica para um novo paradigma chamado de microrregionalização cooperativa. Nessa nova forma de organizar os serviços de saúde, os municípios continuam com sua autonomia, mas podem, se assim desejarem, se organizar de forma cooperativa, pulverizando os serviços de atenção básica e concentrando num município-polo os serviços que exijam uma quantidade maior de procedimentos para que se tenha escala e qualidade adequada, como é o caso dos hospitais (MENDES, 2001).

Também considerando a necessidade de aumento da eficiência e a melhoria na qualidade, e reconhecendo a importância da nova forma de organização dos serviços de saúde, o Ministério da Saúde editou o Pacto Pela Saúde (BRASIL/ MS, 2006), o qual traz consigo essa lógica de organização. Na nova proposição, um hospital que presta serviços apenas no âmbito local teria sua atuação estendida à microrregião ou região em que está situado. A grande questão presente é a resistência de muitos gestores municipais de saúde, os quais, não compreendendo o fenômeno chamado "economia de escala", imaginam que o aumento no número de pacientes irá provocar aumento nos custos, prejudicando os resultados econômicos. Diante disso, surgem as seguintes questôes: É 
economicamente interessante regionalizar a atuação dos hospitais, prestando serviços aos demais hospitais da microrregiāo? Como avaliar a capacidade de um hospital público, inserido no contexto da microrregionalização, em obter resultados econômicos positivos?

\section{Instrumentos para a avaliação econômica em saúde aplicada a hospitais públicos}

Para fazer face às questões de natureza econômica relacionadas também aos hospitais públicos, tem crescido uma disciplina científica chamada "Economia da Saúde". A Economia é definida como a ciência que "estuda a maneira como se administram os recursos escassos, com o objetivo de produzir bens e serviços e distribuí-los para seu consumo entre os membros da sociedade" (TROSTER; MORCILLO, 2002, p. 5). A Economia da Saúde é "o ramo do conhecimento que tem por objetivo a otimização das ações de saúde, ou seja, o estudo das condições ótimas de distribuição dos recursos disponíveis para assegurar à população a melhor assistência à saúde e o melhor estado de saúde possível, tendo em conta meios e recursos limitados"(DEL NERO, 2002, p. 20). Conclui-se então que é justa a relação que se faz entre economia e saúde, pois, como se destaca, o grande problema da Economia é como administrar ou alocar os recursos escassos diante das necessidades ilimitadas, e esse não é outro senão o principal problema na gestão dos serviços de saúde. Assim, diante dos recursos limitados e das necessidades ilimitadas, faz-se necessário estabelecer prioridades no momento da alocação dos recursos públicos, devendo as decisões ser tomadas de forma racional, com base em informações.

Nesse contexto de escassez de recursos, surgiu a avaliação econômica em saúde e seus instrumentos. Esta é definida como "o processo pelo qual os custos de programas, sistemas, serviços ou atividades de saúde são comparados com outras alternativas e suas consequências" (TANAKA; MELO, 2001, p. 43). Quanto aos métodos, ela pode ser classificada em avaliação econômica parcial ou completa. A diferença básica está em quais elementos serão analisados no processo avaliativo.Os principais tipos de avaliação econômica completa são: minimização de custos, custo-efetividade, custo-benefício e custo-utilidade (UGÁ, 1995; GONZÁLEZ, 2004; SILVA, 2004). Para que uma avaliação econômica seja 
considerada completa, ela necessita cumprir dois requisitos básicos: o primeiro é realizar a comparação entre duas ou mais alternativas possíveis, e o segundo é avaliar simultaneamente custos e resultados. Se todos esses requisitos não forem cumpridos, têm-se avaliação parcial e não completa (CASTRO, 2002).

A avaliação econômica tem como principal característica a análise de custos e, para sua efetiva aplicação, ela necessita de um sistema de apuração de custos, o qual produz os dados que serão analisados no processo de avaliação. Um importante instrumento da disciplina de contabilidade que pode auxiliar sobremaneira na análise dos custos, é a chamada análise de custo-volume-superávit. Esse tipo de análise é tradicionalmente conhecido como custo-volume-lucro (MATOS, 2002; BRUNI; FAMÁ, 2004; PADOVEZE, 2006), quando de sua aplicação em empresas privadas. No entanto, visando a aplicar essa mesma técnica de análise a uma entidade pública, Mattos (2007) atribuiu a ela o nome de custovolume-superávit. A nomenclatura se justifica pelo fato de as empresas públicas não visarem ao lucro, mas à prestação de serviços públicos à população.

A aplicação desse tipo de análise é de grande utilidade mesmo numa organização pública, principalmente no contexto da gestão como foco nos resultados, em contraposição ao modelo burocrático. Nesse tom, Silva (2007, p. 21) afirma que a ausência de um sistema apuração de custos, o que possibilita a aplicação dessa análise, impede que a administração pública possa avaliar a utilização dos recursos alocados aos seus agentes e os resultados por eles atingidos.

Se, de forma concomitante à prestação de serviços, alcança-se o superávit, ou minimamente o equilíbrio das contas, isso é algo desejável pelos gestores públicos, em especial os gestores da saúde, pois afinal, “ o dinheiro disponível para a saúde é limitado e, portanto, deve ser utilizado eficientemente e de maneira a maximizar o resultado obtido" (COUTTOLENC, 2001).

\section{Material e método}

Este trabalho é oriundo de uma pesquisa realizada entre os meses de março a novembro de 2008, no Hospital Municipal Roosevelth Figueiredo Lira, em Barra do Bugres, município localizado a $155 \mathrm{~km}$ a noroeste de Cuiabá, capital de Mato Grosso. O Hospital Municipal de Barra do Bugres (HMBB) é uma instituição pública, vinculada ao Sistema Único de Saúde, mantida 
com recursos federais, municipais e oriundos de convênio com a Secretaria de Estado de Saúde de Mato Grosso. De acordo com o Cadastro Nacional de Estabelecimentos de Saúde (CNES, 2007), o hospital tem sua estrutura composta por 80 leitos, divididos entre as clínicas médica, cirúrgica, obstétrica e pediátrica.

A pesquisa foi do tipo "estudo de caso" e, quanto à abordagem, foi de natureza quantitativa, apresentando valores dos diversos tipos de custos e receitas, os quais foram classificados, relacionados e analisados. Ressalta-se que a pesquisa ${ }^{1}$, da qual este artigo é oriundo, foi submetida à apreciação do Comitê de Ética em Pesquisa da Secretaria de Estado em Saúde, conforme protocolo no. 352 CEP/SES/MT, recebendo parecer favorável.

$\mathrm{O}$ dados analisados para este recorte compreenderam o período de 15/10/2008 a 14/11/2008. Numa análise inicial da instituição, verificou-se que a mesma não dispunha de um sistema de apuração de custos, fato que coincide com a constatação de Falk (2008), de que apenas em torno de 15\% dos hospitais brasileiros têm sistemas informatizados de gestão - ou seja, o hospital em estudo não possuía um sistema de informação capaz de produzir as informações nos moldes necessários ao processo de apuração de custos. Diante disso, o primeiro passo foi a estruturação de um sistema de informação baseado em recursos computacionais e no preenchimento de relatórios manuais. Para a produção das informações de maior densidade, desenvolveu-se um software denominado Sistema Integrado de Gestão Hospitalar (SIGHO). Este software foi desenvolvido por um acadêmico bolsista do curso de Ciências da Computação da Universidade do Estado de Mato Grosso (UNEMAT), com apoio financeiro da administração do município sede da pesquisa.

Com a utilização desse software, informatizou-se a produção dos principais dados de consumo e estatísticos dos seguintes setores: recepção, estatística, farmácia, administração, nutrição e limpeza. Foi ainda desenvolvido um módulo específico para a apuraçao dos custos, que possibilitou o processo de rateio e a geração de relatórios de custos. Os objetos de custo escolhidos foram: pacientedia para as unidades de internação e consulta para o pronto-socorro/ambulatório. $\mathrm{O}$ método de custeio escolhido foi o de absorção do tipo RKW, aplicando-se também a classificação dos custos em fixos e variáveis. 
No processo de apuração de custos, optou-se pela classificação do hospital em centros de custos, os quais foram agrupados em quatro tipos: administrativo, intermediário, final e externo. Os custos diretos foram agrupados em três grupos: pessoal e encargos, material de consumo e serviço de terceiros, os quais foram rateados aos centros finais e externos utilizando critérios diversos de rateio, mantendo-se sua classificação quanto à variabilidade, ou seja, em fixos e variáveis. Isso significa dizer que os custos que estavam nos centros administrativos e intermediários classificados como fixos, ao serem rateados aos centros finais e externos, se somaram ao montante de custos fixos já existentes nos centros de destino, o mesmo ocorrendo com aqueles que estavam classificados como variáveis, processo necessário para a análise de custo-volume-superávit. Como custo indireto geral, considerou-se apenas o custo com energia, o qual foi distribuído a todos os centros de custos através de processo de rateio, tendo por base o número de equipamentos existentes em cada centro ponderado por seu tipo e tempo de utilização. Após a apuração dos custos - diretos e indiretos -, foi aplicada a análise de custo-volume-superávit.

Esse tipo de análise é tradicionalmente realizado quando a organização adota em seu sistema de apuração de custos o método de custeio variável ou direto. No entanto, Mattos (2007) aplica com certo grau de sucesso essa mesma análise, utilizando-se do método de custeio por absorção do tipo RKW, com algumas adequações. Um requisito fundamental para que tal análise seja possível é a classificação dos custos quanto ao seu grau de variabilidade em relação ao volume de serviços produzidos, ou seja, em fixos e variáveis. Essa análise de custo-volume-superávit pode ser desdobrada em quatro importantes subtipos de análise: ponto de equilíbrio, margem de contribuição, margem de segurança e alavancagem operacional.

Mattos (2007, p. 3) define ponto de equilíbrio como "aquele nível de atividade, expresso em unidades físicas (pacientes-dia, exames, atendimentos, etc.), no qual os custos se igualam às receitas totais". Ressalta-se que o ponto de equilíbrio pode ser calculado também em unidades monetárias. A margem de contribuição é definida por Padoveze (2006, p. 278) como “ a diferença entre o preço de venda unitário do produto ou serviço e os custos e despesas variáveis por unidade de produto ou serviço". A margem de contribuição é resultante do valor da receita 
unitária menos o custo variável unitário. A margem de segurança é mais uma análise no âmbito da análise custo-volume-superávit que permite visualizar até que ponto o superávit pode ser reduzido sem que a organização chegue ao déficit. Conceituando a margem de segurança numa abordagem voltada para empresas privadas Bruni e Famá (2004, p. 262) a definem como a "quantia ou índice das vendas que excedem o ponto de equilíbrio da empresa. Representa o quanto as vendas podem cair sem que a empresa incorra em prejuízo”. A alavancagem operacional permite a análise dos efeitos que a variação para mais ou para menos nas receitas da organização provocam no resultado, salientando-se, à semelhança da física, que uma força pequena no braço maior de uma alavanca é capaz de mover um peso muito maior no braço menor da alavanca.

As fórmulas para o cálculo da margem de contribuição, ponto de equilíbrio, margem de segurança e alavancagem operacional, são as seguintes: Margem de contribuição ( $\mathrm{MC}=$ Receita unitária - Custo variável unitário); Ponto de equilíbrio em quantidade $(\mathrm{PEQ}=$ Custos fixos / Receita unitária - Custo variável unitário), Ponto de equilíbrio em reais (PE\$ = Custos Fixos / (1-[custos variáveis unitários /receita unitária])); Margem de segurança em quantidade (MSQ = Unidades de serviço vendidas no período - Ponto de equilíbrio em quantidade); Grau de alavancagem operacional ( $\mathrm{GAO}=\%$ de variação no resultado $\div \%$ de variação na receita) (MATOS, 2002; BRUNI; FAMÁ, 2004).

\section{Resultados e discussão}

\section{Análise dos custos totais, custos médios e comparação com a receita}

A tabela 1 evidencia o valor dos custos por cada um dos centros de custos finais e externos. Ressalta-se que nas unidade externas não foi possível calcular o custo médio por unidade de serviço prestado, visto que o valor total representa o custo total de serviços diversos prestados pelo hospital às unidades externas. Dentre estes, os principais são: exames de diversos tipos e roupas lavadas pela lavanderia. Assim, como são serviços diversos não uniformes, torna-se impossível calcular até mesmo o valor médio.

Os dados da tabela 1 indicam uma situação muito preocupante para os gestores do hospital em análise. Consideradas apenas as transferências intergovernamentais e o custo mensal total de $\mathrm{R} \$ 455.526,33$, o HMBB tem um déficit mensal de $\mathrm{R} \$$ 205.908,44, o qual representa $85,9 \%$ da receita oriunda daquelas transferências. 

centros de custos finais, H. M. Barra do Bugres, 15/10 a 14/11/2008

\begin{tabular}{|c|c|c|c|c|c|c|c|}
\hline Tipo de Receita & $\begin{array}{l}\text { Clínica } \\
\text { Cirúrgica }\end{array}$ & Clínica G. 0. & $\begin{array}{l}\text { Clínica } \\
\text { Médica }\end{array}$ & $\begin{array}{l}\text { Clínica } \\
\text { Pediát. }\end{array}$ & P.S. / Amb. & $\begin{array}{l}\text { Unidades } \\
\text { Externas }\end{array}$ & Total \\
\hline $\begin{array}{l}\text { Receitas do SUS } \\
(\mathrm{SIH} / \mathrm{SIA})\end{array}$ & $30.842,82$ & $26.922,75$ & $27.111,99$ & $32.293,44$ & $38.378,50$ & & $155.549,50$ \\
\hline $\begin{array}{l}\text { Receita do Consórcio } \\
\text { Receita do convênio }\end{array}$ & $2.760,98$ & 600,03 & 507,38 & 0,00 & 200,00 & & $4.068,39$ \\
\hline SES/MT & $12.576,18$ & $12.244,42$ & $15.223,78$ & $12.538,38$ & $27.417,23$ & & $80.000,00$ \\
\hline Receita total & $46.179,98$ & $39.767,20$ & $42.843,15$ & $44.831,82$ & $65.995,73$ & & $239.617,89$ \\
\hline Custo total & $63.410,28$ & $88.637,06$ & $73.830,31$ & $61.769,64$ & $125.026,44$ & $32.852,60$ & $445.526,33$ \\
\hline Déficit & $17.230,30$ & $48.869,86$ & $30.987,16$ & $16.937,82$ & $59.030,71$ & $32.852,60$ & 205.908,44 \\
\hline Pacientes-dia & 343 & 273 & 350 & 375 & & & \\
\hline Consultas / exames & & & & & 3.263 & & \\
\hline $\begin{array}{l}\text { Receita média pac.-dia } \\
\text { Receita média por } \\
\text { consulta/exame }\end{array}$ & 134,64 & 145,67 & 122,41 & 119,55 & 20,23 & & \\
\hline $\begin{array}{l}\text { Custo médio pac.-dia } \\
\text { Custo médio } \\
\text { consulta/exame }\end{array}$ & 184,87 & 324,68 & 210,94 & 164,72 & 38,32 & & \\
\hline Déficit médio & 50,23 & 179,01 & 88,53 & 45,17 & 18,09 & & \\
\hline
\end{tabular}

Dentre os centros de custos, nenhum deles é superavitário, com destaque para o pronto-socorro/ambulatório que tem o maior déficit. Quanto à comparação entre a receita média por paciente-dia e o custo médio, o centro que apresenta maior custo médio e consequentemente maior déficit médio é a clínica ginecológica e obstétrica. Um dos fatores que pode ter contribuído para isto foi o grande volume de custos advindos do rateio do centro cirúrgico, em função da grande utilização desse centro de custos para a realização dos partos.

Os resultados indicam a necessidade de medidas por parte dos gestores do sistema local de saúde, no sentido de reduzir e se possível eliminar o déficit existente. Destaca-se também a importância de se conhecer os custos e utilizar essa informação como ferramenta na gestão dos hospitais, especialmente para aqueles que pertencem à rede pública. Embora no hospital em questão sempre se falasse de que o mesmo era deficitário, nenhum estudo mais aprofundado e rigoroso havia sido realizado, para se conhecer a real situação da instituição, objetivando confirmar ou não a existência desse déficit e sua extensão. 
Tratando da importância da existência de sistema de apuração de custos no setor público, Silva (2007, p. 21) afirma que "a ausência de um sistema de custo impede que a administração pública possa avaliar a utilização dos recursos alocados aos seus agentes e os resultados por eles atingidos". Essa é a realidade desse hospital público, já que o mesmo não dispunha de sistema de apuração e controle de custos, impossibilitando aos gestores o conhecimento da real situação econômica do hospital.

É bem verdade que o fim principal do hospital público não é o superávit, mas desejar conciliar a prestação dos serviços necessários com superávit ou ao menos equilíbrio não é nenhum erro - pelo contrário, deve ser um alvo a ser atingido.

\section{Análise da margem de contribuição e ponto de equilíbrio}

A análise da margem de contribuição e do ponto de equilíbrio permite visualisar a capacidade de cada centro de custo final em absorver os custos fixos. Permite também estimar qual o volume de serviços necessários para se alcançar o ponto de equilíbrio, ou seja, o ponto onde não há superávit nem déficit e o resultado é zero, levando em conta a atual estrutura de custos fixos. Nesta análise não foi considerado o centro de custos "unidades externas", pois é impossível calcular o custo médio unitário em virtude da variedade de serviços que ele recebe.

A tabela 2 revela que o valor da margem de contribuição de cada centro custo é positivo, ou seja, as receitas menos os custos variáveis geram resultado positivo, possibilitando o cálculo do ponto de equilíbrio e demonstrando que o hospital é sensível à economia de escala. Um fator que contribuiu para que a margem de contribuição fosse positiva foi a classificação do custo com pessoal como custo fixo. Essa classificação foi adotada em virtude de que mais de $90 \%$ dos servidores do hospital são concursados, não provocando grandes variações nos salários ao longo dos períodos, e as variações que acontecem não têm relação direta com o volume de serviços prestados.

Através da aplicação da fórmula apresentada na metodologia, podese visualizar na tabela 2 o ponto de equilíbrio em quantidade, ou seja, em pacientes-dia $(545,896,815,605)$ para cada uma das clínicas respectivamente, em leitos (92) e em consultas (8.236) para o pronto-socorro/ambulatório. A tabela 2 também demonstra o ponto de equilíbrio em reais para as clínicas e pronto-socorro/ambulatório. 
Como se pode notar, o ponto de equilíbrio em quantidade está bastante acima da capacidade do hospital em quase todas as clínicas, com exceção da pediátrica. Isso indica que, com a atual estrutura de custos fixos e diante da capacidade instalada, o hospital teria condiçōes de alcançar o ponto de equilíbrio somente na clínica pediátrica. Assim, a tabela 2 demonstra que o ponto de equilíbrio para essa clínica seria alcançado com uma produção de 605 pacientes-dia, diante da capacidade instalada de 837 dias-leito. Ressalta-se que para tal resultado seria necessária a manutenção do valor do custo fixo, do custo variável médio e da receita média, e um aumento de 61,3\% no nível de atividade da clínica.

Para que todas as clínicas possam alcançar o ponto de equilíbrio, como demonstrado na penúltima linha da tabela 2 , seria necessário manter o valor de custos fixos, dos custos variáveis médios unitários, da receita média por pacientedia, ampliar o número de leitos para 92 e utilizar $100 \%$ da capacidade instalada. É importante lembrar que esta análise se refere apenas às clinicas, não tomando em conta o déficit de $\mathrm{R} \$ 59.030,71$ do pronto-socorro/ambulatório e de $\mathrm{R} \$$ $32.852,60$ das unidades externas.

Tabela 2 - Distribuição da margem de contribuição e do ponto de equilíbrio, segundo centros de custos finais, H. M. Barra do Bugres, 15/10 a 14/11/2008

\begin{tabular}{|c|c|c|c|c|c|}
\hline Descrição & $\begin{array}{l}\text { Clínica } \\
\text { Cirurg. }\end{array}$ & $\begin{array}{c}\text { Clínica } \\
\text { G. } 0 .\end{array}$ & $\begin{array}{l}\text { Clínica } \\
\text { Médica }\end{array}$ & $\begin{array}{l}\text { Clínica } \\
\text { Pediàt. }\end{array}$ & P.S/Amb. \\
\hline Receitas totais & $46.179,98$ & $39.767,20$ & $42.843,15$ & $44.831,82$ & $65.995,73$ \\
\hline Custos Variáveis & $16.865,84$ & $18.351,85$ & $19.540,51$ & $17.220,91$ & $27.266,08$ \\
\hline Margem de contrib. & $29.314,14$ & $21.415,35$ & $23.302,64$ & $27.610,91$ & $38.729,65$ \\
\hline Pacientes -dia/cons. & 343 & 273 & 350 & 375 & 3.263 \\
\hline Margem cont. unit. & 85,46 & 78,44 & 66,58 & 73,63 & 11,87 \\
\hline Custos Fixos & $46.544,44$ & $70.285,21$ & $54.289,80$ & $44.548,73$ & $97.760,36$ \\
\hline $\begin{array}{l}\text { Ponto de equilíbrio em } \\
\text { quantidade }\end{array}$ & 545 & 896 & 815 & 605 & 8236 \\
\hline Capacidade & 465 & 372 & 589 & 837 & \\
\hline $\begin{array}{l}\text { Ponto de equilíbrio em } \\
\mathrm{R} \$\end{array}$ & $73.323,70$ & $130.516,00$ & $99.814,70$ & $72.333,75$ & $166.584,68$ \\
\hline № leitos necessários & 18 & 29 & 26 & 20 & 92 \\
\hline № de leitos em util. & 15 & 12 & 19 & 27 & 73 \\
\hline
\end{tabular}


Desse modo, o alcance do ponto de equilíbrio nas clínicas não representaria o equilíbrio para todo o hospital. Tal resultado seria possível somente se fossem reduzidos os déficits do pronto-socorro/ambulatório e unidades externas ou se as clínicas produzissem superávit suficiente para cobrir esse déficit, que no período em análise totalizou $\mathrm{R} \$ 91.883,31$. Ressalta-se que esse é um retrato do período atual que tende a se alterar ao longo dos períodos, de acordo com a ocorrência dos eventos que impactam economicamente a organização.

Se um dos objetivos deste trabalho era verificar os efeitos do aumento no volume de serviços prestados pelo hospital, pode-se dizer que o alcançe do ponto de equilíbrio nas clínicas seria possível com a ampliação da quantidade de pacientes-dia. Para atender essa quantidade, o hospital necessitaria possuir um total de 92 leitos, manter o valor do custo variável médio e da receita média unitária e ainda utilizar $100 \%$ da capacidade instalada.

Comparando essa quantidade com a capacidade instalada em utilização atualmente, verifica-se que o hospital teria que aumentar sua estrutura em 19 leitos, manter os mesmos custos fixos, aumentar os custos variáveis e as receitas de forma proporcional e utilizar $100 \%$ de sua capacidade instalada. Ressalta-se que, no período em análise, a taxa de ocupação média geral, a qual indica o grau de utilização da capacidade instalada das clínicas, ficou em torno de 64\%. Isso demonstra também que a debilidade da descentralização se manifesta através da pouca utilização da capacidade instalada, confirmando a validade da proposta da microrregionalização. Os dados indicam também a inviabilidade econômica do hospital diante da atual estrutura de custos e da capacidade instalada. No entanto a quantidade de leitos necessária para se alcançar o ponto de equilíbrio não está tão distante de ser alcançada, embora, como já destacado, esse ponto de equilíbrio seja apenas para as clínicas e não para o hospital em geral.

Esses dados indicam também a necessidade de se trabalhar no sentido de reduzir, se possível, os custos de manunteção do hospital, ou ainda, buscar recursos junto a outros níveis de governo, medidas que poderiam melhorar significativamente a situação econômica da instituição. Assim, pensando no apecto econômico, surge a seguinte pergunta: qual a melhor opção, aumentar ou reduzir o nível de atividade do hospital? O próximo item de análise pode auxiliar na resposta a essa questão. 


\section{Análise da margem de segurança e alavancagem operacional}

Para visualizar o grau de alavancagem operacional, faz-se necessário simular o comportamento da margem de contribuição e do resultado geral da instituição diante da redução ou aumento no nível de atividade. Quanto à margem de segurança, no hospital em estudo nenhum dos centros de custos finais apresentou superávit, tornando-se impossível calculá-la. Afinal, a margem de segurança é a quantidade que a instituição está produzindo acima do ponto de equilíbrio, o que não está ocorrendo no Hospital Municipal de Barra do Bugres. Os dados mostraram que a única clínica que tem condições de alcançar o ponto de equilíbrio com a atual estrutura de custos, receitas e capacidade instalada é a clínica pediátrica.

É importante lembrar que o aumento no volume de serviços prestados pelo pronto-socorro/ambulatório não produzirá o mesmo efeito das clínicas, pois um aumento no nível de atividade desse centro de custo não produzirá aumento de receita. A razão dessa afirmativa é que o Ministério da Saúde estabelece para os hospitais um teto financeiro para cobrança de procedimentos do prontosocorro/ambulatório, sendo que o hospital em análise já está apresentando para cobrança valores quase $100 \%$ maiores que o seu teto financeiro, embora só receba até o limite do teto estabelecido. Desse modo, para esse centro de custo, a melhor alternativa reduzir o número de consultas, o qual está acima do parâmetro estabelecido pelo Ministério da Saúde. A redução no número de consultas provocará, consequentemente, redução nos custos variáveis, diminuindo o déficit desse centro de custos.

Como já apresentado na tabela 1 , é evidente a situação deficitária das quatro clínicas e do pronto-socorro/ambulatório. Supondo que a melhor opção fosse reduzir o nível de atividade, ou seja, diminuir o número de pacientes-dia em $10 \%$, opinião compartilhada por muitos gestores em saúde, a tabela 3 evidencia qual seria o resultado para a instituição. Como na instituição em estudo não houve superávit, mas sim déficit, a fórmula da alavancagem se expressa na clínica cirúrgica, da seguinte forma: \% variação do déficit $(17,01 \%) \div \%$ variação da receita $(10 \%)$. 
Tabela 3 - Distribuição de receitas e custos, segundo centros de custos finais, após redução de $10 \%$ no nível de atividade, H. M. Barra do Bugres, 15/10 a $14 / 11 / 2008$

\begin{tabular}{|c|c|c|c|c|c|}
\hline Custos & $\begin{array}{l}\text { Clínica } \\
\text { Cirurg. }\end{array}$ & $\begin{array}{c}\text { Clínica } \\
\text { G. } 0 .\end{array}$ & $\begin{array}{l}\text { Clínica } \\
\text { Médica }\end{array}$ & $\begin{array}{l}\text { Clínica. } \\
\text { Pediát. }\end{array}$ & P.S/Amb. \\
\hline Receitas totais & $41.561,99$ & $35.790,48$ & $38.558,84$ & $40.348,64$ & $65.995,73$ \\
\hline Custos Variáveis & $15.179,26$ & $16.516,67$ & $17.586,46$ & $15.498,82$ & $27.266,08$ \\
\hline Margem de cont. & $26.382,73$ & $19.273,82$ & $20.972,38$ & $24.849,82$ & $38.729,65$ \\
\hline Custos Fixos & $46.544,44$ & $70.285,21$ & $54.289,80$ & $44.548,73$ & $97.760,36$ \\
\hline Déficit & $-20.161,71$ & $-51.011,39$ & $-33.317,42$ & $-19.698,91$ & $-59.030,71$ \\
\hline
\end{tabular}

Assim, o grau de alavancagem é igual a 1,70 para esta clínica. Esse número indica que para cada $R$ \$ $-1,00$ de variação nas receitas para menos, variação esta oriunda da diminuição no nível de atividade, mantendo-se a receita média unitária e os custos médios unitários constantes, ter-se-ia uma variação negativa de $\mathrm{R} \$-1,70$ no resultado desta clínica e de $\mathrm{R} \$-0,44, \mathrm{R} \$-0,75, \mathrm{R} \$-1,63$ para as demais clínicas, respectivamente.

Suponha-se então, que o nível de atividade fosse aumentado em $10 \%$, e consequentemente, as receitas e os custos variáveis fossem aumentados na mesma proporção, mantendo-se os valores da receita média unitária e do custo médio unitário. A tabela 4 evidencia qual seria o resultado da instituição.

Aplicada a fórmula que calcula o grau de alavancagem, perceber-se-á que o grau será o mesmo da situação anterior. Uma variação positiva de $10 \%$ na receita, fruto do aumento no nível de atividade, mantendo-se a receita média unitária e também o custo médio unitário, provoca uma variação positiva no resultado de 1,70 na clínica cirúrgica, por exemplo. Aplicando-se o conceito da alavancagem, descobre-se que para cada $\mathrm{R} \$ 1,00$ de aumento na receita e, consequentemente, aumento nos custos variáveis e na margem de contribuição, há uma variação positiva no resultado, redução do déficit, nesse caso, em $\mathrm{R} \$ 1,70, \mathrm{R} \$ 0,44, \mathrm{R}$ \$ $0,75, \mathrm{R}$ \$ 1,63 para cada uma das clínicas respectivamente. 
Tabela 4. Distribuição de receitas e custos, segundo centros de custos finais, após elevação de $10 \%$ no nível de atividade, H. M. Barra do Bugres, 15/10 a $14 / 11 / 2008$

\begin{tabular}{|c|c|c|c|c|c|}
\hline Custos & Clínica Cirurg. & $\begin{array}{c}\text { Clínica } \\
\text { G. } 0 .\end{array}$ & $\begin{array}{l}\text { Clínica } \\
\text { Médica }\end{array}$ & $\begin{array}{l}\text { Clínica } \\
\text { Pediàt. }\end{array}$ & P.S/Amb. \\
\hline Receitas totais & $50.797,98$ & $43.743,93$ & $47.127,47$ & $49.315,00$ & $65.995,73$ \\
\hline Custos Variáveis & $18.552,42$ & $20.187,04$ & $21.494,56$ & $18.943,00$ & $27.266,08$ \\
\hline Margem de cont. & $32.245,56$ & $23.556,89$ & $25.632,90$ & $30.372,00$ & $38.729,65$ \\
\hline Custos Fixos & $46.544,44$ & $70.285,21$ & $54.289,80$ & $44.548,73$ & $97.760,36$ \\
\hline Déficit & $-14.298,88$ & $-46.728,32$ & $-28.656,90$ & $-14.176,73$ & $-59.030,71$ \\
\hline
\end{tabular}

Essa simulação demonstra que quando há aumento no nível de atividade, aumentase a receita, os custos variáveis e também a margem de contribuiçãa, no entanto os custos fixos não aumentam, provocando uma variação positiva no resultado. Esse fenômeno é chamado de "economia de escala". Isso indicaria que não é interessante para a instituição diminuir o nível de atividade, o qual é fruto do número de pacientes atendidos? Esse fato é verdadeiro, conforme demonstrado acima, no entanto, não é de todo verdadeiro, fazendo-se necessário analisar mais alguns fatores.

Dados estatísticos do hospital demonstraram que o número de internações de pacientes do município de Barra do Bugres, de junho a novembro de 2008, foi de 293, 298, 286, 318 e 309, respectivamente. Esta quantidade de internações está acima do parâmetro do Ministério da Saúde (243) e do número de Autorizaçoes de Internação Hospitalar (AIH) disponibilizadas ao município (200). Considerando-se esses dados, conclui-se que o hospital deve reduzir o nível de atividade, ou seja, o número de internaçôes somente de pacientes do município, visto que o hospital tem a ocorrência de custos para a quantidade de pacientes que está acima dos 200 (limite de AIHs) e não tem a correspondente receita. Esse fato indica a necessidade de medidas que produzam redução no número das internações de pacientes do município.

Como demonstrado na tabela 4, um aumento no nível de atividade provocou redução e não aumento no déficit, em função da "economia de escala". Assim, 
quando há aumento no nível de atividade, aumentam-se a receita, os custos variáveis e também a margem de contribuição; no entanto, os custos fixos não aumentam, provocando uma variação positiva no resultado. Isso ocorre em função da existência dos custos fixos que não variam de acordo com o nível de atividade. Ou seja, se a clínica cirúrgica tem uma produção no mês de 343 pacientes-dia com o custo fixo de $\mathrm{R} \$ 46.544,44$, qualquer aumento que ocorrer no nível de atividade dentro da capacidade instalada não vai influenciar nesse custo, ou seja, ele será o mesmo.

Isso significa que se for utilizada $100 \%$ da capacidade instalada, o hospital alcançará o ponto de equilíbrio? Essa afirmativa não pode ser feita para todas as clínicas, afinal já foi demonstrado acima que apenas a clínica pediátrica teria condiçôes de alcançar o ponto de equilíbrio com a atual capacidade instalada e o aumento no nível de atividade. Mesmo assim, caso esta clínica alcançasse o superávit, ainda estaria longe de se obter o ponto de equilíbrio para todas as clínicas, reduzindo apenas o déficit geral. No entanto, caso o hospital elevasse o nível atividade até $100 \%$ da capacidade instalada, já que no período o grau de utilização da capacidade foi de $64 \%$, haveria significativa redução do déficit e não aumento dele, em virtude exatamente da "economia de escala".

Conforme já destacado anteriormente, esse aumento no nível de atividade teria que ocorrer através do aumento do número de usuários oriundos de outros municípios e não do município de Barra do Bugres, para que a receita também aumente proporcionalmente ao incremento na atividade. Quanto às internações do próprio município, há necessidade de reduzi-las para que seu número máximo não ultrapasse o limite de AIHs disponíveis para o município (200). Assim, a redução no número de pacientes do município atendidos pelo hospital irá proporcionar redução no déficit através da diminuição desses custos, e da disponibilização da estrutura do hospital para a oferta de serviços para a microrregião. O recebimento de pacientes de outros municípios e consequentemente, suas Autorizações de Internação Hospitalar (AIH), irá aumentar o número de AIHs que o município encaminhará para a cobrança, já que as AIHs desses município irão se somar às 200 AIHs do município, aumentando a receita do hospital.

Dessa forma, a resposta à pergunta levantada no final do subitem anterior é que o hospital deve reduzir o nível de atividade em relação aos pacientes do próprio município e elevar o nível de atividade em relação aos pacientes dos 
outros municípios da microrregião, obtendo como consequência melhoria nos

resultados econômicos. Isso será possível, no entanto, somente através da melhoria na articulação microrregional e efetivação do hospital como referência para a microrregião. Esses dados demonstram que a expansão da atuação do hospital para a microrregião trará resultados econômicos positivos, aumentando a receita e em seu caso específico, reduzindo o déficit existente.

\section{Considerações finais}

Este trabalho evidenciou a importância da avaliação econômica e da utilização de técnicas da contabilidade de custos, como instrumentos capazes de produzir informaçôes úteis ao processo de tomada de decisões e melhoria da eficiência hospitalar.

A análise de custo-volume-superávit demonstrou que, com a atual estrutura de custos e capacidade instalada, apenas a clínica pediátrica teria condições de alcançar o superávit, embora ainda não o tenha alcançado. Demonstrou também que, mantendo os custos fixos, a receita média e a margem de contribuição média, o hospital seria capaz de obter o ponto de equilíbrio para as clínicas com a ampliação de sua estrutura para 92 leitos e a utilização de $100 \%$ dessa estrutura. No entanto, essa análise não levou em consideração o pronto-socorro/ ambulatório e as unidades externas, os quais são deficitários. Esta análise também evidenciou a inviabilidade econômica do hospital com a atual estrutura de custos e capacidade instalada.

Em resposta às duas primeiras perguntas elencadas na introdução deste trabalho, os dados apresentados demonstraram que o aumento no nível de atividade hospitalar, viabilizado pela microrregionalização, naqueles hospitais que têm ociosidade na utilização da capacidade instalada, é economicamente interessante, já que normamente nos hospitais o custo fixo tem grande representatividade. No hospital em estudo este custo representa 74,2\%. Ressalta-se que as referidas medidas somente terão efeitos se aliadas a uma forte articulação microrregional nos moldes da microrregionalização cooperativa proposta por Mendes (2001) e promovida pelo Ministério da Saúde através do Pacto pela Saúde.

Assim, de forma contrária ao que pensa grande parte dos gestores em saúde, o que pode ser atribuído à falta de qualificação para a gestão, no caso dos hospitais de médio porte, o recebimento de pacientes dos demais municípios, é 
interessante economicamente, pois provoca aumento de receita, diante da grande representatividade dos custos fixos, melhorando os resultados econômicos e não aumentando o déficit, como se imagina.

Este artigo comprovou a importância da avaliação econômica e da aplicação da análise de custo-volume-superávit como um instrumento para se analisar os custos de hospitais públicos e também a capacidade destes em gerar resultados econômicos positivos. A limitação neste trabalho foi a impossibilidade de se analisar os efeitos da economia de escala em vários de períodos de atividade do hospital, de modo a se analisar o comportamento dos resultados econômicos e da eficiência da organização ao longo do tempo. Recomendam-se novas pesquisas para o aprimoramento das técnicas utilizadas para a avaliação econômica aplicada aos hospitais públicos.

\section{Referências}

BRASIL. Conselho Nacional de Secretários de Saúde. SUS: avanços e desafios. 1. ed. Brasília: CONASS, 2006.

BRASIL. Ministério da Saúde. Secretaria de Atenção à Saúde. DATASUS. Cadastro Nacional de Estabelecimentos de Saúde - CNES. Brasília: Ministério da Saúde, 2007. Disponível em: http://cnes.datasus.gov.br/Lista_Es_Nome.asp?VTipo=0 Acesso em: 27 nov. 2007

BRASIL. Ministério da Saúde. Secretaria Executiva. Coordenação de Apoio à Gestão Descentralizada. Diretrizes operacionais para os pactos pela vida, em defesa do SUS e de Gestão. Brasília: Ministério da Saúde, 2006.

BRUNI, A.L.; FAMÁ, R. Gestão de custos e formação de preços: com aplicações na calculadora HP 12C e Excel. 3. ed. São Paulo: Atlas, 2004.

CASTRO, J.D. Instrumentos para avaliação econômica dos serviços de saúde. In: ENCONTRO NACIONAL DE ECONOMIA DA SAÚDE, 6. 2002, Nova Friburgo. Anais. Brasília: IPEA/Ministério da Saúde/DIFID, 2002.

COUTTOLENC, B.F. Por que Avaliação Econômica em Saúde? Rev. Ass. Med. Brasil, v. 47, n. 1, p. 1-23, 2001.

DEL NERO, C.R.O. O que é Economia da Saúde. [acesso em 15 de novembro de 2007]. Disponível em: http://www.ppge.ufrgs.br/ats/disciplinas/2/nero-2002.pdf

FALK, J.A. Tecnologia de informação para gestão de custos e resultados no hospital: considerações e dicas para implantação de um modelo brasileiro. São Paulo: Atlas, 2008. 
GONZALEZ, A.M.G. Economía de la salud en el contexto de la salud pública cubana. Rev

Cubana Salud Pública. [online]. oct.-dic. 2003, v. 29, n. 4, p. 0-0. Disponível em: http:// scielo.sld.cu/scielo.php Acesso em 12 set. 2007.

MATOS, A.J. Gestão de custos hospitalares: técnicas, análise e tomada de decisão. São Paulo: Editora STS, 2002.

MATTOS, J.G. Análise de custo-volume-superávit para o Hospital Universitário da UFSC. Disponível em: http://www.gea.org.br/scf/custos.html Acesso em: 10 out. 2007.

MENDES, E.V. A organização da saúde no nível local. São Paulo: Hucitec, 1998.

MENDES, E.V. Os grandes dilemas do SUS: tomo II. Salvador: Casa da Qualidade Editora, 2001.

MINAS GERAIS. Secretaria de Estado de Saúde. Pacto de gestão: da municipalização autárquica à regionalização cooperativa. Belo Horizonte; 2004.

PADOVEZE, C.L. Curso básico gerencial de custos. 2. ed. rev. e ampl. São Paulo: Pioneira Thompson Learning, 2006.

SILVA, C.A.T. et al. Custos no setor público. Brasília: Editora UNB, 2007.

SILVA, M.G.C. Introdução à Economia da Saúde. Fortaleza: EdUECE, 2004.

TANAKA, Y.O.; MELO, C. Avaliação de Programas de Saúde do Adolescente: um modo de fazer. São Paulo: EdUSP, 2001.

TROSTER, R.L.; MORCILLO, F.M. Introdução à Economia. Edição revista e atualizada. São Paulo: Pearson Makron Book, 2002.

UGÁ, M.A.D. Instrumentos de avaliação econômica dos serviços de saúde: alcances e limitaçôes.1995, 209-27. Disponível em: www.ppge.ufrgs.br/ats/disciplinas/2/uga-1995.pdf Acesso em: 12 set. 2007.

\section{Nota}

${ }^{1}$ Este artigo é oriundo de uma pesquisa de Mestrado em Saúde Coletiva, realizada na Universidade Federal de Mato Grosso, a qual teve a dissertação apresentada e aprovada dia 03/04/2009 e tem por título Avaliação econômica em saúde: um estudo de caso do Hospital Municipal de Barra do Bugres - MT. 
Is it economically viable to regionalize the performance of a public hospital of medium size?

The efficiency of public health is a growing management need, especially in public hospitals. These organizations are complex because of the multiplicity of services and the high costs involved. So this paper evaluates a hospital in the state of Mato Grosso, Brazil, by the method of "costvolume-surplus". The results show among other things, that the reduction of excess capacity from the increased number of patients from other cities would produce an increase in revenues due to economies of scale, providing the process of decentralization of SUS (microregionalization) with systemic efficiency.

> Key words: Economic evaluation, hospital costs, hospital management. 